\title{
Codebô: Um puzzle game educacional sobre Estrutura de Dados
}

\author{
Luan Silva Gomes \\ STEAM \\ Universidade Salvador \\ Feira de Santana, Bahia, Brasil \\ luangms@outlook.com
}

\author{
Luis Gustavo J. Araujo \\ STEAM \\ Universidade Salvador \\ Feira de Santana, Bahia, Brasil \\ luis.araujo@unifacs.br
}

Estrutura de Dados (ED) é um importante componente dos cursos de Computação. No entanto, despertar o interesse e manter a motivação dos estudantes diante de conceitos abstratos é um desafio. Assim, muitos professores buscam por soluções pedagógicas para este problema [1]. Dentre estas soluções, a Game Based Learning destaca-se pela sua possibilidade de interação, engajamento e aprendizagem ativa [2]. No entanto, não existem muitos jogos sobre ED e, nos poucos jogos existentes, as decisões de game design não possibilitam uma imersão nos tópicos. Um estudo mostra que a maioria dos jogos brasileiros sobre ED utilizam os conceitos como tema do jogo e não como mecânica (e.g., Quiz e Simulação) [3]. Em geral, muitas ferramentas educacionais focam na visualização [1], o que não é suficiente para a aprendizagem [4]. Estudantes aprendem melhor experimentando, explorando e predizendo resultados [2]. Assim, este trabalho visa apresentar um jogo que busca possibilitar a experimentação, focando em objetivos educacionais mais elevados como Aplicar e Analisar [5] por meio de mecânicas baseadas em estruturas de dados.

Codebô é um code puzzle game, similar ao Lightbot [6] para ensino de ED, desenvolvido por meio do Design interativo [7] e educacional [8]. O enredo do jogo compreende em levar o personagem (Codebô) até o seu planeta. Em cada fase, é preciso transportá-lo da posição inicial até a bandeira, por meio de comandos do tipo movimento, relacionados à ED e coleta de itens. Em cada fase, existe um limite razoável para o uso de comandos, possibilitando várias estratégias para resolução do puzzle. $\mathrm{O}$ Codebô possibilita aos jogadores interação com as estruturas Pilha, Fila e Lista, permitindo exploração, análise e a predição de ações. Além disso, fornece instruções e feedbacks em forma de Pop-ups e console (mensagens de alerta e erro).

A Figura 1 apresenta a fase 3 do mundo Pilha. Ao entrar na fase, o jogador visualiza o mapa, a bandeira e o Codebô (personagem), botões de reload, menu, stop e play. O jogador pode adicionar ou remover comandos em uma sequência que é executada ao clicar no botão play. O personagem se move por meio dos comandos de movimento: frente, esquerda e direita. No entanto, só Fica permitido ao(s) autor(es) ou a terceiros a reprodução ou distribuição, em parte ou no todo, do material extraído dessa obra, de forma verbatim, adaptada ou remixada, bem como a criação ou produção a partir do conteúdo dessa obra, para fins não comerciais, desde que sejam atribuídos os devidos créditos à criação original, sob os termos da licença CC BY-NC 4.0.

EduComp'21, Abril 26-30, 2021, Jataí, Goiás, Brasil (On-line)

C2021 Copyright mantido pelo(s) autor(es). Direitos de publicação licenciados à Sociedade Brasileira de Computação (SBC). é possível movimentar-se por blocos do mesmo nível em que o personagem está. Para acessar outros níveis, o jogador precisa utilizar os comandos referentes à Pilha: pop(), push(codebo), push(bloco) [9]. Nesta fase, o jogador precisa criar uma pilha, empilhar um bloco e empilhar o personagem, fazendo-o acessar o nível 2. Após isso, o jogador precisa desempilhar o personagem para que ele saia da pilha (LIFO) e volte ao mapa. Ao chegar na bandeira, a fase termina. O número de blocos utilizados e a coleta de itens são considerados para contabilizar os pontos das fases.

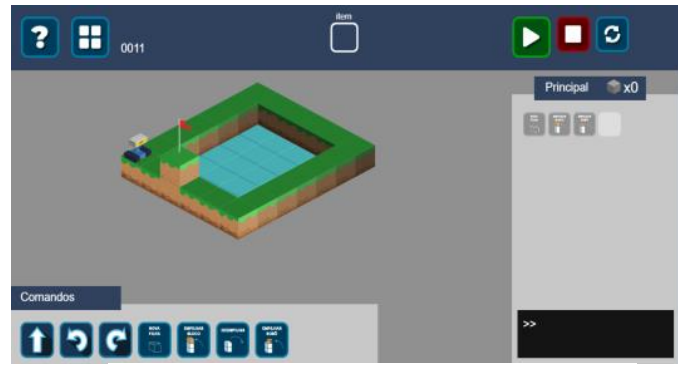

Figura 1: Fase 3, Mundo Pilha.

Nos mundos Fila e Lista, o Codebô utiliza as estruturas para acessar locais isolados no mapa. Na Fila, os blocos e o Codebô são sempre inseridos ao fundo e a remoção dos itens é sempre pela frente (FIFO). As Listas, no entanto, permitem que o personagem se mova entre os blocos. Paras as Listas Simplesmente Encadeadas, o Codebô pode se mover em uma direção (ida). Para as Listas Duplamente Encadeadas, é possível mover-se nas duas direções (ida e vinda). Além das Estruturas de Dados, o Codebô conta com itens coletáveis e que podem ser utilizados para modificar o mapa ou o movimento. Existem três itens: Ponte (permite criar uma ponte em uma local sem bloco), Buraco Negro (permite se transportar para uma região do mapa) e Espelho (permite espelhar a criação de blocos no mapa).

Ao abordar os conceitos de ED como mecânica, o jogo Codebô expande um campo para estudo do uso de jogos neste componente. Como trabalhos futuros, objetiva-se concluir todos os levels do jogo e avaliá-lo [10]. Após esta etapa, serão desenvolvidas propostas de atividades e Guia do Professor. Todos os materiais estão disponíveis em: https://sites.google.com/view/codebo-game/. 


\section{AGRADECIMENTOS}

Agradecemos à FAPESB, financiadora da bolsa de Iniciação Cientifica, assim como à Coordenação de Pesquisa da UNIFACS, pelos suportes prestados.

\section{REFERÊNCIAS}

[1] Arnold Pears, Stephen Seidman, Lauri Malmi, Linda Mannila, Elizabeth Adams, Jens Bennedsen, Marie Devlin, and James Paterson. 2007. A survey of literature on the teaching of introductory programming. In Working group reports on ITICSE on Innovation and technology in computer science educatio (ITiCSEWGR '07). Association for Computing Machinery, New York, NY, EUA, 204 223. DOI:https://doi.org/10.1145/1345443.1345441

[2] Darina Dicheva and Austin Hodge. 2018. Active Learning through Game Play in a Data Structures Course. In Proceedings of the 49th ACM Technical Symposium on Computer Science Education (SIGCSE '18). Association for Computing Machinery, New York, NY, EUA, 834-839. DOI:https://doi.org/10.1145/3159450.3159605

[3] Luan S. Gomes, Luis G. Araujo, 2020. Uma proposta de avaliação e construção de jogo educacional como suporte do processo de ensino-aprendizagem de estrutura de dados. In: Proceedings of $16^{a}$ Jornada UNIFACS de Iniciação Científica (JUIC' 20). Universidade Salvador, Salvador, BA, BR, 1-4. ISSN 2237-3055.

[4] Christopher D. Hundhausen, Sarah A. Douglas, John T. Stasko, 2002. A MetaStudy of Algorithm Visualization Effectiveness. 2002. Visual Languages \& Computing, 13, 3 (junho 2002), 259-290. DOI: https://doi.org/10.1006/jvlc.2002.0237.

[5] Lorin W. Anderson, David R. Krathwohl, Peter W. Airasian, Katheleen A. Cruikshank, Richard E. Mayer, Paul R. Pintrich, James Raths, Merlin C. Wittrock. 2001 A taxonomy for learning, teaching and assessing: a revison of Bloom's Taxonomy of Educational Objectives. Addison Wesley Longman, Nova York, NY.

[6] GOUWS, Lindsey Ann; BRADSHAW, Karen; WENTWORTH, Peter. Computational thinking in educational activities: an evaluation of the educational game light-bot. In: Proceedings of the 18th ACM conference on Innovation and technology in computer science education. 2013. p. 10-15.

[7] Eric Zimmerman, Katie Salen. 2012. Regras do jogo: fundamentos do design de jogos. Blucher, São Paulo, SP.

[8] Luis G. Araujo, Jorge C. Leite Junior, 2015. Estado de Fluxo e Zona de Desenvolvimento Proximal: A aprendizagem do jogador como elemento norteador do Game Designer. In Proceedings of Simpósio Brasileiro de Games e Entretenimento Digital (SBGAMES' 15). SBC, Teresina, PI, BR. ISSN: 2179 2259.

[9] Robert Lafore. 2017. Data structures and algorithms in Java. Prenhall, Indianápolis, IN.

[10] Fong-Ling Fu, Rong-Chang Su, and Sheng-Chin Yu. 2009. EGameFlow: A scale to measure learners' enjoyment of e-learning games. Comput. Educ. 52, (January, 2009), 101-112. DOI:https://doi.org/10.1016/j.compedu.2008.07.004 